\title{
Tachycardia-polyuria syndrome after swan-ganz catheterization in liver transplant patient - A case report -
}

\section{Sang-Kwon Heo', Kyoung-Sun Kim², Jeong-Hyun Lee' ${ }^{1}$, and Jun-Gol Song ${ }^{2}$}

${ }^{1}$ Department of Anesthesiology and Pain Medicine, Seoul Medical Center, ${ }^{2}$ Department of Anesthesiology and Pain Medicine, Laboratory for Cardiovascular Dynamics, Asan Medical Center, University of Ulsan College of Medicine, Seoul, Korea

Received January 13, 2021

Revised April 26, 2021

Accepted April 26, 2021

Background: Tachycardia-polyuria syndrome is characterized by polyuria occurring because of tachycardia with a heart rate of $\geq 120$ beats/min lasting $\geq 30 \mathrm{~min}$. We report such a case occurring after swan-ganz catheterization.

Case: A 41-year-old male was scheduled for living-donor liver transplantation. After general anesthesia, atrial fibrillation occurred during swan-ganz catheterization, and polyuria developed $1 \mathrm{~h}$ later. During the anhepatic phase, the patient's heart rate increased further, and cardioversion was performed. After a normal sinus rhythm was achieved, the patient's urine output returned to normal.

Conclusions: The patient's polyuria seemed related to the iatrogenic atrial fibrillation occurring during swan-ganz catheterization. Although we did not measure atrial natriuretic peptide, an increase in its concentration may have been the main mechanism of polyuria, as natriuresis was observed.

Keywords: Antidiuretic hormone; Atrial fibrillation; Atrial natriuretic peptide; Polyuria; Swanganz catheter.

Tachycardia-polyuria syndrome is characterized by the onset of polyuria after tachycardia with a heart rate (HR) of $\geq 120$ beats/min persisting for at least $30 \mathrm{~min}$ [1]. Multiple case reports of polyuria in patients with paroxysmal supraventricular tachycardia have been published [1-3]. A reduction of antidiuretic hormone $(\mathrm{ADH})$ and secretion of atrial natriuretic peptide (ANP) are known to be involved in this phenomenon $[4,5]$. This phenomenon more commonly affects patients with paroxysmal atrial fibrillation (a-fib) than it does those with a valvular disease or chronic heart failure $[1,3,6]$. Here, we report a case of a-fib during insertion of a swan-ganz catheter, followed by polyuria during living-donor liver transplantation surgery.

\section{CASE REPORT}

This case report was exempted from the need of obtaining the patient's informed consent by the Institutional Review Board (IRB) of Asan Medical Center (no. 2021-0047).

A 41-year-old male, diagnosed with hepatocellular carcinoma, was admitted for a living-donor liver transplant. The patient ( $179.1 \mathrm{~cm}$ and $87.7 \mathrm{~kg}$ ) was a carrier of the hepatitis $B$ virus and had liver cirrhosis with a Child-Pugh score of 5 and a model for end-stage liver disease score of 7 . The patient had no notable medical history other than hypertension. No notable findings were obtained from the chest X-ray, electrocardiogram (ECG), transthoracic echocardiog-

This is an Open Access article distributed under the terms of the Creative Commons Attribution Non-Commercial License (http://creativecommons.org/licenses/by-nc/4.0) which permits unrestricted non-commercial use, distribution, and reproduction in any medium, provided the original work is properly cited.

Copyright (C) the Korean Society of Anesthesiologists, 2021 
raphy, coronary artery computed tomography, brain magnetic resonance image (MRI), lung function test, blood tests, and arterial blood gas analysis performed at the time of admission.

After arrival at the operating room, the patient's blood pressure, ECG, and oxygen saturation $\left(\mathrm{SpO}_{2}\right)$ were monitored; all his vital signs were normal. Anesthesia was induced with midazolam (5 mg), propofol (130 mg), rocuronium (100 mg), and fentanyl (100 $\mu \mathrm{g})$. Following endotracheal intubation, anesthesia was maintained with desflurane (4$5 \%$ ) and continuous infusion of fentanyl and rocuronium. We placed a catheter in the right radial artery, two catheters in the right internal jugular vein, and a catheter in the right subclavian vein to secure access to a central vein.

While inserting a swan-ganz catheter, the patient's ECG re- vealed a-fib with a rapid ventricular response (RVR) (Fig. 1). We administered a beta blocker (esmolol), which did not markedly change the ECG. The patient's vital signs at the time were as follows: arterial blood pressure, 107/71 $\mathrm{mmHg}$; $\mathrm{HR}, 137$ beats/min; $\mathrm{SpO}_{2}$, 99\%. The arrhythmia lasted for about $9 \mathrm{~min}$, and a normal heart rhythm was spontaneously achieved. To avoid further a-fib, we retracted the swan-ganz catheter to a depth of $15 \mathrm{~cm}$ and attempted to fully reinsert it after 20 min; however, a-fib with a RVR occurred again (Fig. 2). The patient was immediately given a beta blocker (esmolol), but the arrhythmia persisted; thus, an anti-arrhythmic agent (amiodarone) was continuously infused. The patient's other vital signs remained stable, and transesophageal echocardiography also revealed no notable findings other than a-fib. Hence, we decided to continue the surgery while carefully

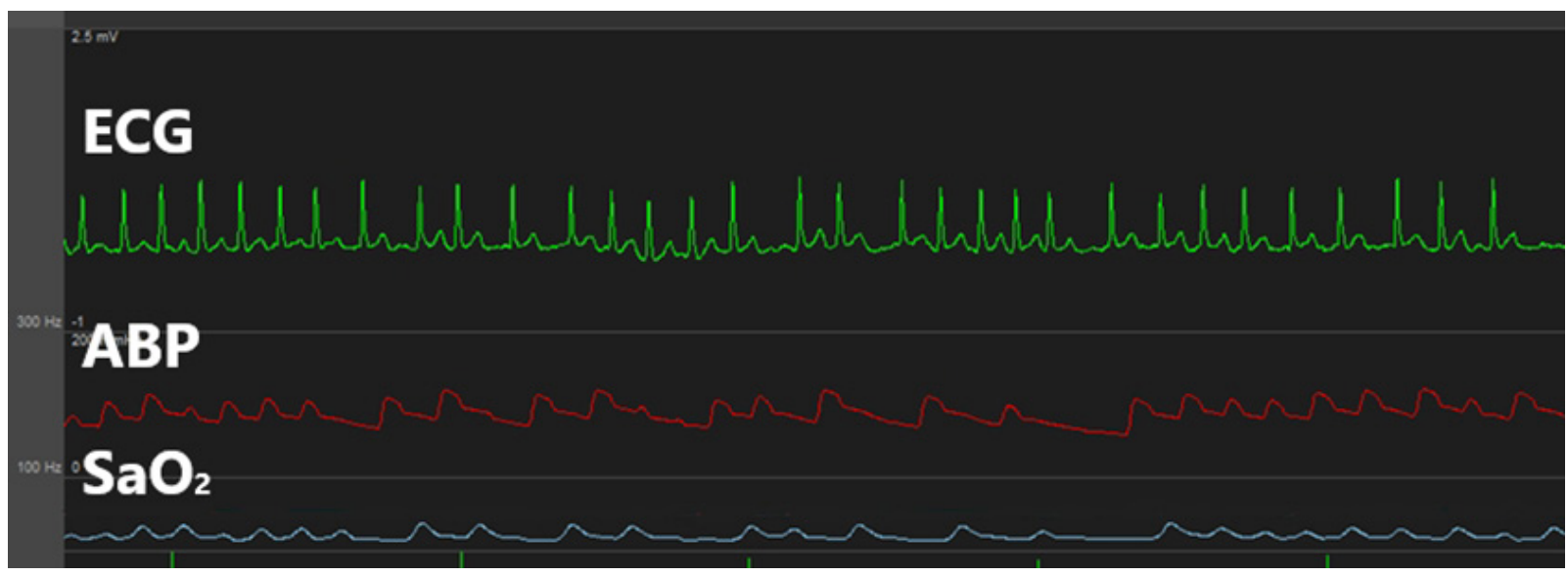

Fig. 1. This is atrial fibrillation occurred when swan-ganz catheter was inserted. ECG: electrocardiogram, ABP: arterial blood pressure.

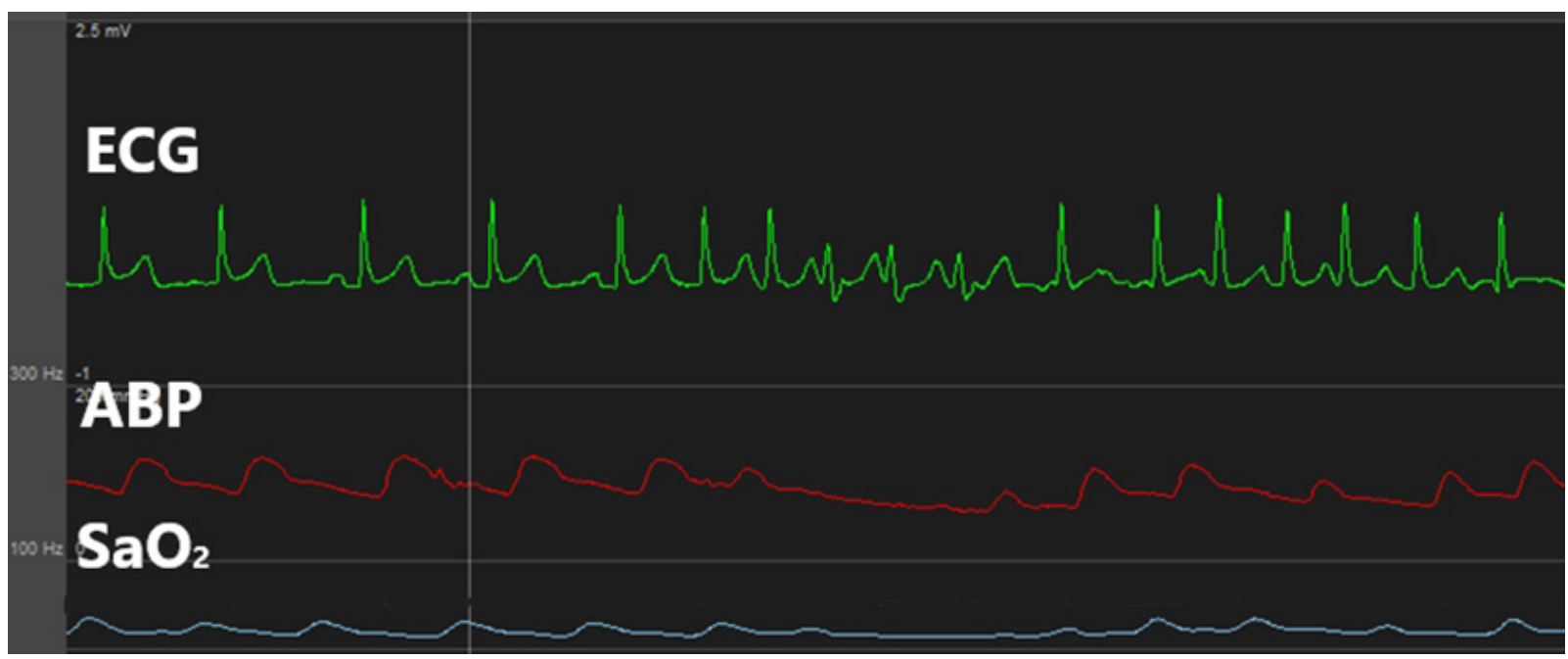

Fig. 2. This is atrial fibrillation occurred when swan-ganz catheter was re-inserted. ECG: electrocardiogram, ABP: arterial blood pressure. 
monitoring the patient.

Urine output (U/O) measured as soon as the surgery commenced was abnormally high $(1,000 \mathrm{ml} / \mathrm{h})$. We suspected polyuria due to tachycardia [2,3,5-7] and, thus, performed urine analysis (U/A) and plasma ADH testing. The results indicated natriuresis (sodium clearance, $18.6 \mathrm{ml} / \mathrm{min}$; osmolar clearance, $16.6 \mathrm{ml} / \mathrm{min}$; $2 \times$ urine sodium/urine osmolarity, 0.88) (Fig. 3). During the anhepatic phase, the patient's HR increased further and exhibited hemodynamic instability; hence, direct current (DC) cardioversion (50 J) was performed, after which a normal rhythm was achieved (Fig. 4). U/O measured one hour later was markedly decreased and natriuresis was reduced (sodium clearance, $3.7 \mathrm{ml} / \mathrm{min}$; osmolar clearance, $3.6 \mathrm{ml} / \mathrm{min} ; 2 \times$ urine sodium/urine osmolarity, 0.81) (Fig. 3).
The surgery proceeded without notable problems, after which the patient was transferred to the intensive care unit (ICU). The patient's ECG revealed normal rhythms until the end of surgery. At the ICU, the patient exhibited a normal U/ $\mathrm{O}$ and ECG, with stable vital signs, and, after being transferred to a general ward, the patient was discharged without any further problems.

\section{DISCUSSION}

We reported a case of tachycardia-polyuria syndrome that occurred during insertion of a swan-ganz catheter in a liver transplant patient.

According to Wood [1] and Luria et al. [3], tachycardia-polyuria syndrome is defined as polyuria that occurs in approxi-
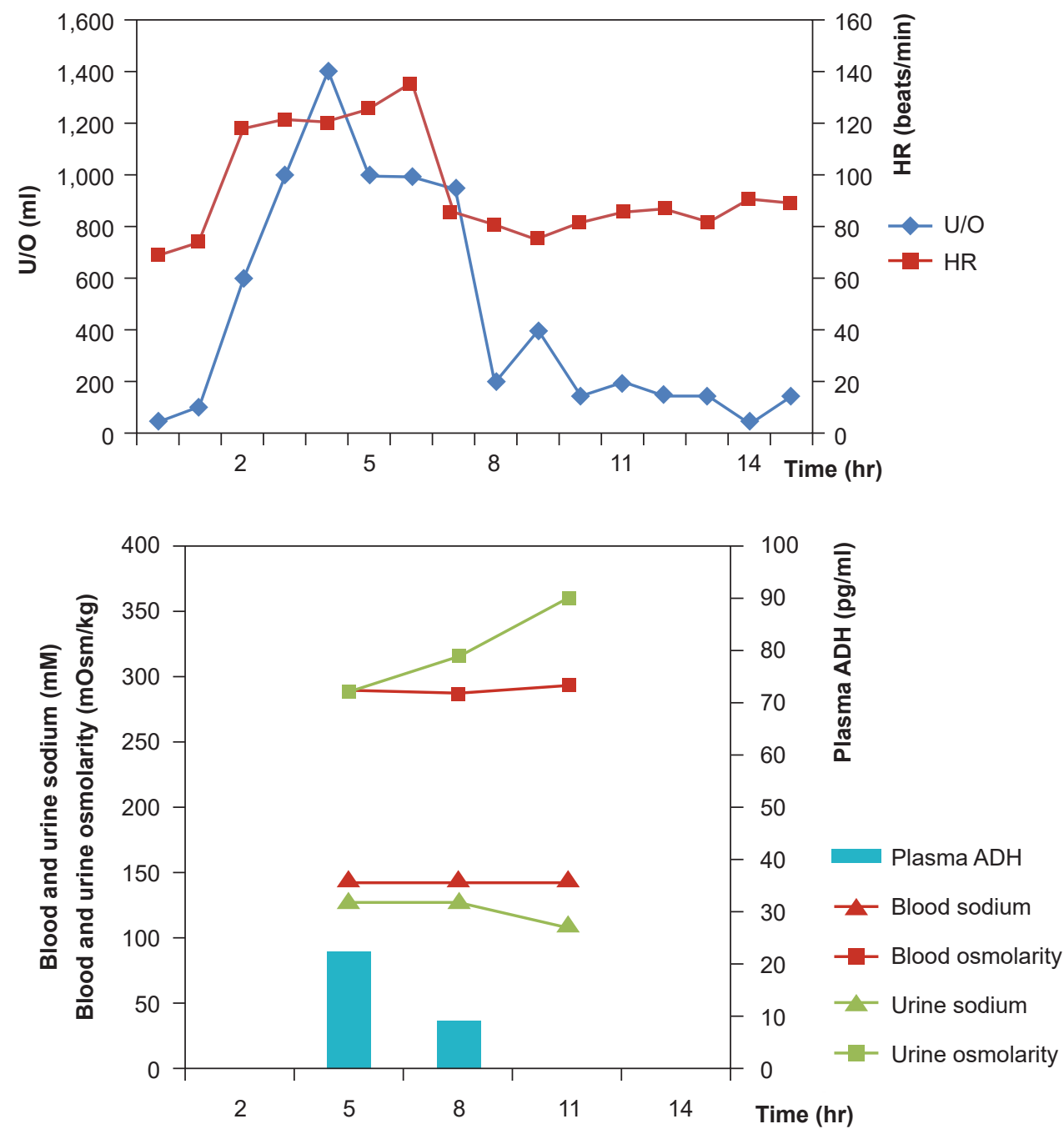

Fig. 3. Chart showing the heart rate, urine analysis, urine output and blood test changes. HR: heart rate, U/O: urine output, ADH: antidiuretic hormone. 
mately half of patients with paroxysmal supraventricular arrhythmias faster than 110 beats/min lasting for $\geq 20 \mathrm{~min}$ in the absence of left ventricular failure and stenotic valvular lesions, and there are no clear diagnostic criteria for this syndrome. ADH and ANP are known to be potentially involved in the mechanism underlying tachycardia-polyuria syndrome $[2,4,5,7,8]$. In addition to receiving blood into the heart and releasing it into the ventricles, the atria also serve the function of detecting and regulating the intravenous volume. This process, which begins with the atrial receptors, is known to involve neuronal and hormonal networks such as $\mathrm{ADH}$ and ANP [4]. An elevation of venous return in the body leads to atrial distention, which stimulates the atrial receptors [9]. These receptors depolarize the afferent vagal nerve to decrease the efferent sympathetic and vasomotor tones of the renal nerve, and to reduce $\mathrm{ADH}$ activity, thereby inducing diuresis [6].

Polyuria refers to an abnormally high output of diluted urine (i.e., $\geq 3 \mathrm{~L} / 24 \mathrm{~h}$ or $\geq 40-50 \mathrm{ml} / \mathrm{kg} / 24 \mathrm{~h}$ ). It can be caused by a variety of factors, and these conditions are collectively referred to as polyuria-polydipsia syndrome. The causes can be broadly classified into three factors: central diabetes insipidus (CDI), nephrogenic diabetes insipidus (NDI), and primary polydipsia. Because the causes and treatments for each of these factors differ, differential diagnosis is crucial [10]. The patient in this case had no abnormal preoperative brain MRI findings and had no history of endocrine diseases such as diabetes mellitus or renal diseases. Further, the patient had a normal electrolyte balance during surgery, and none of the medications administered intraoperatively were known to induce polyuria. Therefore, we could eliminate CDI and NDI from the diagnosis. The patient developed polyuria during induction of anesthesia, allowing us to eliminate volume overload. In essence, the patient's polyuria seemed related to the iatrogenic a-fib that occurred during insertion of the swan-ganz catheter during induction of anesthesia.

It has been reported that paroxysmal a-fib induces atrial pressure and atrial volume expansion in canines under anesthesia [11]. Similarly, the a-fib observed in our patient is believed to have induced atrial volume expansion and, consequently, atrial wall distention, which would have led to a suppression of $\mathrm{ADH}$ and, thereby, caused diuresis. However, contrary to the mechanism of tachycardia-polyuria syndrome as it is currently understood, our patient had a higher-than-normal plasma ADH concentration.

$\mathrm{ADH}$ is known to regulate water absorption through the expression of aquaporin-2 on the V2 receptors of the collecting duct, and its production increases in response to increased plasma osmolality, reduced atrial pressure, and reduced intravascular volume [12]. Fuji et al. [8] reported that $\mathrm{ADH}$ may be increased to suppress water diuresis caused by supraventricular tachycardia, and that elevated $\mathrm{ADH}$ levels increased renal prostaglandin E2, thereby inducing natriuresis independently from ANP. Thus, the elevated ADH in our case seems to be a compensation mechanism to counteract the reduction of intravascular volume caused by polyuria, as opposed to being the cause of polyuria.

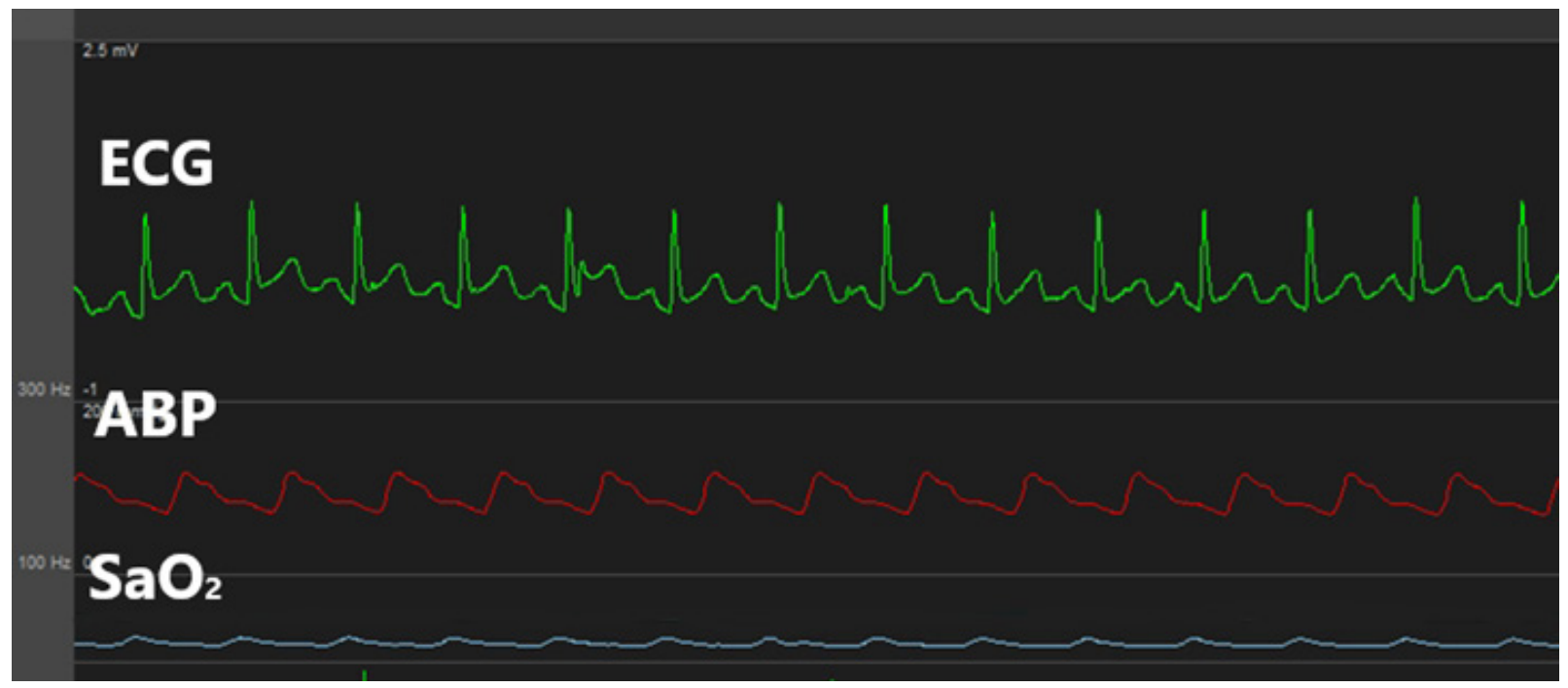

Fig. 4. This is atrial fibrillation occurred when swan-ganz catheter was re-inserted. ECG: electrocardiogram, ABP: arterial blood pressure. 
ANP, which serves an essential role in tachycardia-polyuria syndrome, is a cardiac hormone secreted as a result of stretching of the atrial cardiocytes [13], and elevated atrial pressure is an important factor involved in its production [5]. ANP regulates the intravascular volume by blocking renin, angiotensin, and aldosterone secretion to induce natriuresis and diuresis [14]. Kinney et al. [2] reported that U/O is increased in tachycardia-polyuria syndrome as a result of natriuresis through sodium clearance, osmolar clearance, the ratio of sodium to osmolarity in urine $(2 \times$ urine sodium / urine osmolarity), and that sodium accounts for a high percentage of the excreted solutes. In the present case, U/A performed after the onset of tachycardia indicated natriuresis. This suggests that sodium excretion was the cause of the observed diuresis [2].

One hour after achieving a normal rhythm, test results confirmed that natriuresis was reduced and, consequently, ANP levels would have been lowered $[4,5]$. Further, an animal study revealed that atrial pressure increased by $81 \pm$ $19 \%$ and atrial diameter by $21 \pm 5 \%$ during a-fib [11]. Taken together, increased ANP seems to be the main mechanism of tachycardia and polyuria accompanied with natriuresis. However, the fact that we did not measure ANP concentration is a limitation to our report.

The Society of Cardiovascular Anesthesiologists/European Association of Cardiothoracic Anaesthetists published a practice advisory for the management of perioperative a-fib in patients undergoing cardiac surgery, with several recommendations [15]. According to the practice advisory, perioperative a-fib should be treated with non-dihydropyridine calcium channel blockers or beta blockers (strength of recommendation =1). If the patient is hemodynamically unstable, they should be treated with electrical or chemical (e.g., amiodarone) cardioversion (strength of recommendation = 1). Moreover, amiodarone is recommended (strength of recommendation $=2 \mathrm{a}$ ) to prevent $\mathrm{a}$-fib after cardiac surgery. However, when unresponsive tachycardia occurs, as in the present case, DC cardioversion may be necessary to achieve a normal sinus rhythm.

The present case highlighted the possibility that iatrogenic a-fib occurring during insertion of a swan-ganz catheter may cause polyuria. Polyuria during surgery has a great influence on the patient's volume management. Therefore, an anesthesiologist must be familiar with the discrimination and treatment about perioperative polyuria. Notably, if atrial fibrillation is the cause of polyuria, DC cardioversion could be a way to stop polyuria if the drug does not respond.

\section{CONFLICTS OF INTEREST}

No potential conflict of interest relevant to this article was reported.

\section{DATA AVAILABILITY STATEMENT}

All data generated or analyzed during this study are included in this published article. This is a case report.

\section{AUTHOR CONTRIBUTIONS}

Conceptualization: Jun-Gol Song. Data curation: Sang-Kwon Heo. Writing - original draft: Sang-Kwon Heo. Writing - review \& editing: Kyoung-Sun Kim, Jeong-Hyun Lee, Jun-Gol Song. Investigation: Sang-Kwon Heo. Supervision: Jeong-Hyun Lee, Jun-Gol Song.

\section{ORCID}

Sang-Kwon Heo, https://orcid.org/0000-0002-1868-9454 Kyoung-Sun Kim, https://orcid.org/0000-0002-6643-9177 Jeong-Hyun Lee, https://orcid.org/0000-0002-7535-4095 Jun-Gol Song, https://orcid.org/0000-0002-6076-6978

\section{REFERENCES}

1. Wood P. Polyuria in paroxysmal tachycardia and paroxysmal atrial flutter and fibrillation. Br Heart J 1963; 25: 273-82.

2. Kinney MJ, Stein RM, DiScala VA. The polyuria of paroxysmal atrial tachycardia. Circulation 1974; 50: 429-35.

3. Luria MH, Adelson EI, Lochaya S. Paroxysmal tachycardia with polyuria. Ann Intern Med 1966; 65: 461-70.

4. Hirata Y, Nozaki A, Toda I, Murakawa Y, Sugimoto T, Matsuoka $\mathrm{H}$, et al. Plasma concentration of atrial natriuretic polypeptide in patients with atrial tachycardia. Jpn Heart J 1987; 28: 53-61.

5. Nilsson G, Pettersson A, Hedner J, Hedner T. Increased plasma levels of atrial natriuretic peptide (ANP) in patients with paroxysmal supraventricular tachyarrhythmias. Acta Med Scand 1987; 221: 15-21.

6. Zullo MA. Atrial regulation of intravascular volume: observations on the tachycardia-polyuria syndrome. Am Heart J 1991; 122(1 Pt 1):188-94.

7. Canepa-Anson R, Williams M, Marshall J, Mitsuoka T, Lightman S, Sutton R. Mechanism of polyuria and natriuresis in atrioventricular nodal tachycardia. Br Med J (Clin Res Ed) 1984; 289: 866-8. 
8. Fujii T, Kojima S, Imanishi M, Ohe T, Omae T. Different mechanisms of polyuria and natriuresis associated with paroxysmal supraventricular tachycardia. Am J Cardiol 1991; 68: 343-8.

9. Paintal AS. A study of right and left atrial receptors. J Physiol 1953; 120: 596-610.

10. Nigro N, Grossmann M, Chiang C, Inder WJ. Polyuria-polydipsia syndrome: a diagnostic challenge. Intern Med J 2018; 48: 244-53.

11. White CW, Kerber RE, Weiss HR, Marcus ML. The effects of atrial fibrillation on atrial pressure-volume and flow relationships. Circ Res 1982; 51: 205-15.

12. Treschan TA, Peters J. The vasopressin system: physiology and clinical strategies. Anesthesiology 2006; 105: 599-612; quiz 639-
40.

13. Cantin M, Genest J. The heart and the atrial natriuretic factor. Endocr Rev 1985; 6: 107-27.

14. Laragh JH. The endocrine control of blood volume, blood pressure and sodium balance: atrial hormone and renin system interactions. J Hypertens Suppl 1986; 4: S143-56.

15. O’Brien B, Burrage PS, Ngai JY, Prutkin JM, Huang CC, Xu X, et al. Society of Cardiovascular Anesthesiologists/European Association of Cardiothoracic Anaesthetists practice advisory for the management of perioperative atrial fibrillation in patients undergoing cardiac surgery. J Cardiothorac Vasc Anesth 2019; 33: 12-26. 